\title{
Ergonomics Programs and Activities in Research Libraries
}

\section{Susan Cook Summer}

\begin{abstract}
A survey of ergonomics activities and programs in research libraries produced evidence of the degree to which libraries are creating formal organizational structures to address ergonomics. Data were gathered that describe whether libraries are providing ergonomics equipment and accessories, whether libraries are offering ergonomics training sessions, whether ergonomics training and activities are focused on technical services departments, and whether concerns about ergonomics have had an impact on job descriptions or office design. An overview of current awareness and trends is given and some promising ideas for addressing ergonomics issues are identified through a closer look at a few very active programs.
\end{abstract}

\section{A} arm injuries in computer users has propelled the field of ergonomics onto center stage. The increasing number of musculoskeletal injuries suffered stems primarily from vast increases in computer use in offices, schools, and homes, where people perform thousands of repetitive motions for hours at a stretch, often sitting at badly arranged workstations. Other people have been plagued by back, shoulder, and neck strains from poor materials-handling techniques in the lifting and transporting of books, computer equipment, and heavy boxes.

These injuries affect many types of office workers, including journalists, telephone operators, data entry staff, word processors, and dozens of others. The injuries come in a variety of degrees, forms, nomenclatures, and acronyms, including several types of repetitive stress injuries (RSI), repetitive motion injuries, and cumulative trauma disorders (CTD), such as tendinitis and carpal tunnel syndrome. While such injuries have long been known to musicians, factory workers, and employees in the food industry, they are now afflicting what is currently the nation's largest occupational group: computer users. Although most injuries can be prevented or caught and treated at an early stage, others are much more serious.

This "epidemic" has raised public consciousness about ergonomics, the study of how we interact with our physical work

SusAn COOK SUmmer is Slavic Cataloger and NACO Coordinator, Columbia University Libraries, New York (summer@columbia.edu). The author thanks all those who responded to the survey and particularly acknowledges the extensive materials and comments supplied by: Carmel Bush, assistant director for Technical Services, Colorado State University Libraries; Judith A. Mansfield, Workplace Ergonomics Program Coordinating Committee, Library of Congress; and Nancy Lucas, head, Periodical Reading Room/Microforms, and member of the Ergonomics Awareness Committee, Michigan State University Libraries. The author also thanks Veronica Ghetie, Office of Environmental Health and Safety, Columbia University. Manuscript received February 9, 1995; revised and accepted for publication August 4, 1995. 
environment. It has spawned a large amount of literature, training, occupational therapy, networking, and legislation aimed at its prevention and cure. For instance, the United States Occupational Safety and Health Administration (OSHA) has drafted proposed regulations for federal ergonomics standards that would require companies to assess ergonomic risks and take steps to reduce the possibility of repetitive stress injuries. If and when adopted, the regulations would cover approximately 120 million workers nationwide (Thyfault 1994, 20). While these complex regulations will take time to finalize and adopt, some states have already drafted or ratified similar legislation.

Newspapers, popular magazines, and television have all given ergonomics broad press coverage. A 1992 two-part New York Times article, "Epidemic at the Computer: Hand and Arm Injuries," outlined the problem and offered a list of ways to reduce the risk of injury (Brody 1992). Hundreds of more specialized articles, journals, and books have focused on specific aspects of working at computers. Many of these, such as OSHA's 1991 publication Working Safely with Video Display Terminals (U.S. Dept. of Labor 1991), include diagrams of recommended workstation set-up, exercises, and checklists for computer operators. Dozens of newsletters, RSI support groups, and listservs have sprung up during the past few years. (Electronic resources include Sorehand and RSINET: Repetitive Strain Injury Newsletter.) Unions and labor relations boards have organized seminars on ergonomics to discuss the prevention of RSI, the proposed federal legislation, and workers' compensation.

In response to the great number of injuries, some hospitals have established clinics to treat patients suffering from RSI. The Miller Health Care Institute at St. Luke's-Roosevelt Medical Center in New York, established in 1985 to treat musicians with injuries, now treats a growing number of computer operators. Its director, Dr. Emil Pascarelli, coauthored a book entitled Repetitive Strain Injury: A Computer User's Guide (Pascarelli and
Quilter 1994), which offers a seven-point program for the prevention and treatment of RSI.

Computer supplies and product design likewise reflect the increased concern with ergonomics. In addition to adjustable office chairs and computer tables, equipment catalogs now include a large assortment of wrist rests, antiglare screens, telephone headsets, foot rests, and online programs that periodically remind users to refocus their eyes, exercise, or take a quick stretch break. One example is ExerciseBreak, a program of pop-up windows with stretch and relaxation exercises.

Keyboard design is under new scrutiny as companies experiment with models designed to encourage typing with hands and wrists in a more neutral position, reduce overuse of the right hand, and channel some keying away from the weakest fingers. This includes a whole slew of "ergonomic" keyboards featuring variations on conventional key arrangement, tilt, or the shape and contour of the keyboard itself. Apple Computer was the first to develop a keyboard that splits into two pieces. Microsoft introduced the "Natural Keyboard," and many other companies have likewise experimented in this area (Manes 1994). Advertising has adopted ergonomics as a catchword, using it in descriptions of not only office equipment, but of car and airplane seats, cameras, scissors, and many other tools used in workshops, kitchens, and gardens.

Concerns about ergonomics have engendered a brand new area of fitness, with a wealth of publications, videos, and online programs devoted to well-being at the office. These include exercise routines for the hands and arms, eye exercises, and guidelines for seated and standing posture. For example, Eyercize is a software program that interrupts the operator at periodic intervals and leads eye exercises. Articles on ergonomics report handouts, training, and exercise programs sprouting up in settings as diverse as the offices of Microsoft, Lawrence Livermore National Laboratory, the clothing manufacturer OshKosh B'Gosh, and LSG/Sky Chefs, the airline caterer (Ubols 1992; Fefer 1994). 


\section{INCREASED AWARENESS OF ERgONOMICS IN LIBRARIES}

Libraries have become increasingly automated during the last decade. In addition to building and maintaining online catalogs, staff members in circulation, reference, collection development, binding preparation, serials control, interlibrary loan, personnel, and administration are all spending more time at their computer keyboards. In addition, nearly all related tasks are likewise computer-dependent: word processing for correspondence, reports, memos, and procedural documentation; statistics compilation; electronic mail; and use of the Internet for dozens of applications. Increasing numbers of newsletters and journals are also changing to online formats. And, the movement in libraries away from the card catalog, the typewriter, and paper files has greatly decreased formerly built-in physical activities like rolling in typewriter paper, pulling out catalog drawers, and walking across the office to consult manual files. In short, in many institutions streamlined workflows combined with reduced staff have resulted in staff members being increasingly tied to their computers with less offline work to mix into their daily routines.

This new environment has resulted in an increase in RSIs and in a growing awareness of ergonomic issues in libraries. There is now a rich literature on ergonomics and libraries in monographs, journal articles, and electronic resources. The majority of these publications focus on ergonomically sound principles of workstation arrangement, posture, and work habits. Others discuss ergonomics as an aspect of library management, including its relation to automation, organizational change, space planning, equipment budgets, and personnel issues. While many authors are concerned with computerdependent technical services departments, more attention is being given to reference and circulation service points, as well as to patron workstations.

Ergonomics has also been discussed in a number of postings on the AUTOCAT discussion list, where librarians have reported recent increases in carpal tunnel injuries and staff members out for surgery or on disability. Some postings have mentioned the establishment of staff training in ergonomics and the purchase of adjustable furniture and computer accessories such as wrist rests. Others have discussed job restructuring or job sharing intended to provide staff with more noncomputer work and thereby reduce RSIs.

The Library of Congress (LC) gopher, MARVEL, includes a series of articles on ergonomics written by Barbara Bryant. The first of these estimated that "eight out of every 100 LC employees suffer workrelated injuries" caused by repeated physical stresses and "outdated workstation design and poor materials-handling techniques, along with the lack of employee training programs" (Bryant 1993). Subsequent articles reported significant improvements due to ergonomics training through a library-wide Workplace Ergonomics Program, workstation evaluations, and the purchase of improved furnishings. The program trained literally hundreds of LC staff members. Some of LC's training is based on courses given by the Joyce Institute, a Seattle-based firm specializing in ergonomics. In 1991 and 1992 this included the institute's "Datahealth Ergonomics Seminars" and "Practical Office Ergonomics," attended by several hundred people, as well as the certification of a number of LC staff members as key trainers. In 1991 LC's Collections Services Visual Display Terminal (VDT) Ergonomics Committee produced a laminated handout called "Ergonomics and VDT Use," which was distributed to LC staff, with another 7,500 copies later sent to more than five hundred libraries around the country. The broadside was reissued in 1992. Many libraries distributed copies or based local ergonomics handouts on LC's publication.

Ergonomics has been the discussion topic at several library conference sessions, including the meeting of the Association for Library Collections \& Technical Services LITA Serials Automation Interest Group at the ALA Midwinter 
Conference in January 1993 (Ten Have 1993). Approximately fifty out of about sixty attendees reported work-related injuries at their institutions. Reports from Michigan State University Libraries and the University of Chicago Library both stressed the importance of increased staff awareness of ergonomics and RSI, training programs, the purchase of fully adjustable furniture, and the provision of computer accessories including foot rests, antiglare screens, and wrist rests. The fall 1994 NOTIS Users' Group Meeting (NUGM) also featured a session on ergonomics. Attendees received copies of the LC ergonomics handout, a checklist for posture and work habits, recommended exercises, a bibliography, and information on related electronic resources.

\section{EARLIER SURVEY}

A few years ago, Elizabeth N. Steinhagen and Carolyn J. Mueller, both from Humboldt State University Library, conducted a survey of ergonomics activities at 185 medium-sized academic libraries and published their results in a 1992 issue of Technical Services Quarterly (Steinhagen and Mueller 1992). The ninety-eight usable responses they received indicated that "in spite of the fact that the majority $(81 \%)$ of the libraries represented have online public access catalogs, and thus would be expected to provide reduced opportunities for work away from a VDT, at this time there is no apparent imbalance in online and non-VDT responsibilities" (Steinhagen and Mueller 1992, 34). The noncomputer tasks listed in the survey returns included off-terminal editing and cataloging, shelflist/card catalog maintenance, processing activities, filing/revision, and authority work. Steinhagen and Mueller also found that ergonomic furniture (other than adjustable chairs) and accessories were not widely used in the libraries surveyed. The most common items reported were pneumatically adjustable chairs $(50 \%)$, window blinds $(42 \%)$, and antiglare screens (41\%). Responses about what the respondents would like if funding were available in- cluded fully ergonomic workstations $(79 \%)$ and computers at individual desks (63\%).

\section{Summary OF Results OF THIS SURVEY}

The present survey was designed to assess the current state of ergonomics programs and activities in research libraries in terms of factors including: (1) whether libraries are establishing formal ergonomics committees or programs; (2) whether libraries are buying much ergonomics equipment and accessories; (3) how much libraries are incorporating ergonomics concerns into the design or renovation of offices and departments; (4) what libraries are offering in terms of ergonomics training programs; (5) whether job descriptions or union negotiations are reflecting concerns about ergonomics; (6) how many libraries have experienced work-related ergonomic injuries; (7) whether staff members have raised questions and concerns about ergonomics; and (8) where innovative or "model" programs are in place.

A questionnaire was sent to 104 heads of technical services at ARL libraries, and fifty-four responses were returned. In addition, five people responded to an AUTOCAT posting asking for descriptions of ergonomics programs at libraries that had not received the questionnaire. The results clearly show that ergonomics has become an important topic in libraries and that ergonomics training, equipment, and accessories are now widespread.

The first section asked whether librarians had established formal ergonomics committees or programs and, if so, what categories and levels of staff were involved. Seventeen reported they had formed ergonomics committees or programs, while thirty-seven had not. A number of respondents noted that their committees were formed during the past three years, while others said they were actively planning to appoint such a group because of the increasing need and concern for ergonomics. Committee members primarily include professional librarians and paraprofessional staff, with some also re- 
porting involvement by administrators and others, including facility designers and consultants from university health services. Nearly all committees reported working in conjunction with other departments, including library personnel (13), library systems offices (7), and the university office of health and safety (15). In addition, some committees reported working with the university labor relations department, the facility design department, and the training and development office. One mentioned working with the university-wide ergonomics officer, who provides workstation evaluation, cost estimates for upgrade and design, training programs and literature, and eye exams for computer users.

These committees' major areas of activity are workstation design, training programs, and literature distribution. Two completed questionnaires listed conducting exercise sessions, while three listed activities like acquiring ergonomic accessories and publishing lists of recommendations. Not a single committee or program reported limiting its activities to technical services units.

The second section of the questionnaire asked what ergonomic equipment and supplies libraries are purchasing. The replies showed that virtually all libraries are buying some ergonomic equipment and that many are supplying a wide variety of different items. These results show a marked increase over the findings by Steinhagen and Mueller (1992).

Adjustable chairs topped the list, with fifty-two libraries (96\%) reporting. This was followed by wrists rests (50 libraries, or $93 \%$ ), antiglare screens and document holders (49 libraries, or $91 \%$ each), foot rests (44 libraries, or $81 \%$ ), adjustable tables or workstations (39 libraries, or 72\%), and acoustic printer pads or covers (22 libraries, or $41 \%)$. Other items listed included humidifiers or dehumidifiers, adjustable monitor arms, split keyboards, keyboard/mouse trays, mechanical lifting devices, sorting stools, and back supports for staff who do shelving.

In response to whether such items were available for all staff or only when requested, twenty-two respondents checked "for all staff," while forty-three checked "only when requested." This section elicited numerous comments, many of which were common to several libraries. A number of respondents said that, while such equipment is theoretically available to all staff, general practice has been to provide things upon request when someone has noticed a particular problem through a workstation review. Several others reported that adjustable furniture and ergonomic equipment and accessories were being introduced on a gradual or piecemeal basis, often tied into office renovations, the introduction of new equipment, or annual equipment budgets. Some respondents said that small items (e.g., antiglare screens, wrist rests, and foot rests) were available throughout the year, with larger purchases (furniture) purchased annually. One respondent mentioned that even when staff have adjustable chairs and workstations, "they seldom seem to take advantage of those features." A few said they were only beginning to move in the direction of supplying ergonomic equipment and accessories. Some of these reported that their institution was coordinating the purchase of these items with the selection of integrated systems that will put computers on all staff desks, while others reported that they were hampered by budgetary constraints.

Ergonomics concerns are being incorporated into office renovation and design. For example, eighteen reported the use of sound-absorbent flooring, walls, and ceiling tiles. Fourteen reported the use of recessed lighting, eleven reported using nonreflective paint, nine reported tinted window glass, and three listed other items, such as reduced lighting.

While only seventeen reported formal ergonomics committees or programs, ergonomics education and training have become widespread. Thirty-two distribute handouts or articles, thirty-one offer seminars or workshops for computer users, twenty-four listed workstation evaluations, nineteen offer seminars or workshops to avoid lower-back injuries, and thirteen show training videos. A few offer eye exams for computer users, exercise 
sessions, and other training sessions, such as "wellness programs" that include ergonomics among other topics.

Ergonomics is also beginning to factor into the design of job descriptions. Thirteen reported that jobs have been revised or redesigned to take ergonomics into account, while forty-one reported that no such changes have been made. Ten reported that union negotiations have included concerns or stipulations about ergonomics or ergonomic equipment, while thirty reported that they have not. A number of respondents noted that unions are currently pursuing issues related to ergonomics. While many have not incorporated ergonomics into job descriptions, there is clearly a trend to take such factors into consideration. One respondent added in the margin: "They should!" Some questionnaires listed informal changes to daily routines, such as identifying "nonworkstation activities to vary staff assignments" and other similar practices. Many libraries do not have unionized staff, and therefore skipped the question.

The last section of the survey focused on whether staff members have had workrelated ergonomic injuries and whether they have raised questions or concerns about ergonomics. Eighty-three percent reported injuries. Many of those reporting injuries said multiple staff members at their libraries had experienced carpal tunnel syndrome and other types of repetitive stress injuries, some of which required physical therapy, splints, or surgery. Fifty-three reported that staff members had raised concerns about ergonomics, and forty-five reported that the provision of ergonomics training or equipment seems to improve staff morale and effectiveness.

\section{Some Model Programs}

In addition to providing an overall picture of ergonomics activities in libraries, the survey results-along with the literature and handouts some respondents enclosed-also identified a few institutions with extremely active, broad, and innovative programs. Some brief examples follow.

\section{COLORADO STATE UNIVERSITY LIBRARIES}

Initiated in 1990, the ergonomics program at Colorado State University Libraries is coordinated by the personnel librarian, who works in conjunction with a consultant from University Health Services. Additional input is provided by the Assistive Technology Resource Center of the Department of Occupational Therapy and the library building proctor.

The program includes a number of "standard features," such as conducting ergonomic evaluations for all staff members and acquiring ergonomics accessories and equipment based on the results of the evaluations. In addition, the program organizes seminars for computer users, seminars about avoiding lowerback injuries, video showings, a checklist for comfort at the computer, and extensive handouts and literature. The activities are available both to paraprofessional staff (who spend approximately $44 \%$ of their time at computers) and to professional staff (who spend approximately 28\%).

The Colorado program has also incorporated ergonomics into performance appraisals, which have a section called "Emergency, security, safety and ergonomics." This includes evaluation in terms of: advocacy for safety and ergonomics; making suggestions for improvements; serving as a role model; and "observing ergonomic principles in the handling of materials and in appropriate adjustments to the workstation" (Bush 1994). Among the factors listed in the appraisal form are: observing ergonomic practices prescribed during the review; performing required exercises; taking breaks from the computer as recommended; reporting ergonomic problems; and using proper body mechanics for lifting and transporting materials. Supervisors are responsible for seeing that the practices are positively reinforced and for monitoring the ergonomic situation within the unit. The appraisal is tied into a policy statement issued by the Colorado State University Libraries that specifies the ergonomics responsibilities of the administration, per- 
sonnel department, supervisors, employees, and building proctors.

\section{LIBRARY OF CONGRESS}

The Library of Congress Workplace Ergonomics Program covers all positions throughout the enormous LC system, including both staff who work at computers and staff who perform various types of materials-handling, such as using booktrucks to transport books, manuscripts, and motion pictures. Approximately $40 \%$ of both professional and paraprofessional staff spend more than six hours per day at the computer, with another $22 \%$ using the computer for more than four hours per day.

The program's main component is "formal surveillance and job analysis and design using tools, including survey instruments, as specified in the 1990 OSHA draft for an ergonomics program" (Mansfield 1994). This includes looking for risk factors through videotaping, completing checklists, and workflow analysis. The committee works with the Office of Health and Safety, the Facility Design and Construction Office, and the Staff Training and Development Office. In addition to many "standard" ergonomics accessories (e.g., adjustable furniture, antiglare screens, wrist rests and foot rests, etc.), staff members receive, as needed, book holders and mechanical lifting devices to deal with the more than thirty-one thousand items received daily. The committee issued a poster series on proper VDT work habits, a broadside on VDT exercises, and the nationally distributed broadside on proper VDT workstation configuration. The articles posted on MARVEL give additional information about this large program.

\section{Columbia UNIVERSITY LIBRARIES}

Columbia's program began in early 1992 with a six-member Glare Screen Task Force, appointed to evaluate and select antiglare screens for technical services departments when a major workflow reorganization was putting computers on every desk for the first time. The work of the task force identified many related questions, leading to the appointment of a permanent group with a broader focus. The group now includes a six-member committee working with a group of "coordinators," representing a total of twentytwo library units or departments. The group works very closely with the Office of Environmental Health and Safety and has developed a multifaceted program of training and activities.

The Environmental Health and Safety Office provides expertise in the form of: (1) periodic workshops and extensive handouts on working safely with VDTs and on avoiding lower-back injuries in materials handling; (2) personal audits of individual workstations and the training of committee members and coordinators to conduct such audits; (3) the loan of training videos; and (4) special problem resolution as needed, such as measuring light levels and evaluating the materials-handling techniques of staff who do large amounts of lifting or reshelving.

The committee and coordinators serve as "local experts" or resource people in their units. Their responsibilities include: (1) maintaining and distributing articles and handouts, many of which have been compiled into standardized "Ergonomics Literature Notebooks"; (2) performing workstation reviews, including the recommendation of accessories such as wrist rests, foot rests, task lamps, copy stands, and antiglare screens, as needed; (3) testing and evaluating new equipment and accessories; (4) serving as liaisons to the committee chair and the Office of Environmental Health and Safety to help identify problems and develop solutions; and (5) planning training events.

The configuration of the committee and coordinators and their ties to the Environmental Health and Safety Office have spread ergonomics awareness and training throughout the libraries and have created a framework for broad and systematic staff orientation, training, and problem resolution.

\section{Michigan STATE UNIVERSITY}

A particularly active and comprehensive program is sponsored by the Ergonomics Awareness Committee of Michigan State 
University Libraries. Known as the "Ergobusters," this group includes administrators, professional staff, and paraprofessionals. They assist both professional staff, who spend varying amounts of time at the computer, and paraprofessional staff, who spend between $75 \%$ and $80 \%$ of their time at the computer. The group's activities include workstation design, training, publicity, and extensive follow-up evaluation. Its work is closely tied to the university's comprehensive ergonomics policy, implemented in response to a sharp increase in cumulative trauma disorders. This policy recommends "routine and widespread consideration of ergonomics issues" and includes mandates for training, workstation design, job design, medical management, and individual compliance. The libraries' own Ergonomic Statement of Responsibility builds on this, particularly emphasizing the importance of staff morale and safety. The committee's work has resulted in a significant drop in workers' compensation claims and a boost in morale.

A major component of the committee's activity involves workstation evaluation, for which they have developed a series of checklists: (1) background surveys (e.g., staff member's height, vision problems, work habits, physical discomforts noticed); (2) chair evaluation forms used to compare and contrast sixteen points about three different chair models; and (3) a four-page worksite evaluation form with sections on chairs and seating, keyboards and arm positioning, VDTs, comments made both before and after evaluations and corrective actions, and sections for both individual and shared workstations. They also put together a number of handouts, workstation checklists, recommended exercises, and bibliographies. The Ergobusters are authorized to order inexpensive items (such as wrist rests and monitor stands) as part of their evaluations. The Ergobusters have also assisted with improving the larger working environment. They have, for instance, ordered partitions to reduce noise in the technical services division and ordered curtains and changes in lighting to reduce glare in the business library.
In addition to working with full-time staff members, the Ergobusters are collaborating with the Student Advisory Committee to give ergonomics training to the libraries' six hundred student employees. They have also given "Supervisor Ergonomic Awareness" seminars in which they suggest ways for supervisors to prevent work-related injuries and ways supervisors can help injured workers return to work.

\section{Summary and Conclusions}

The results of this survey indicate a growing availability of ergonomics training, equipment, and accessories in research libraries. This is true of libraries both with and without formal ergonomics programs. Some of this activity has been driven by increasing numbers of work-related ergonomic injuries such as carpal tunnel syndrome. Furthermore, some libraries are incorporating ergonomics concerns into job descriptions, union negotiations, and office design and renovation.

There is a clefinite increase in the number of libraries establishing formal ergonomics committees or programs, although this number is still relatively small. For libraries that do have such programs, the committee structure and mandate have enabled participants to organize and provide standardized training in ergonomics and materials-handling to large numbers of staff. In addition, these committees provide a forum and network for problem identification and resolution, as well as an official channel to relevant services in departments such as personnel, library systems, and campus health and safety.

\section{Works CrTeD}

Brody, Jane. 1992. Epidemic at the computer: Hand and arm injuries. New York Times, March 3, Cl; March 4, Cl4.

Bryant, Barbara. 1993. Ergonomics: LC workers risk injury. Library of Congress gazette 19 Nov. In MARVEL [database online]. Available from: gopher://marvel.loc.gov/ 11/employee/health/ergonomics.

Bush, Carmel. 1994. Survey response and correspondence with author.

Fefer, Mark D. 1994. Taking control of your 
workers' comp costs. Fortune, Oct. 3, 13136.

Manes, Stephen. 1994. Odd keyboards may help you type: On the other hand, they may not. New York times, Sept. 27, C8.

Mansfield, Judith A. 1994. Survey response and electronic mail to author.

Pascarelli, Emil, and Deborah Quilter. 1994. Repetitive strain injury: A computer user's guide. New York: Wiley.

Steinhagen, Elizabeth N., and Carolyn J. Mueller. 1992. Ergonomics and the catalog librarian. Technical services quarterly 9 , no. 4: 29-42.

Ten Have, Elizabeth D. 1993. Prevention of repetitive strain injuries: Report of the
ALCTS/LITA Serials Automation Interest Group Meeting, American Library Association, Midwinter Meeting, Denver, January 1993. Technical services quarterly 11, no. 2: 71-75.

Thyfault, Mary E. 1994. OSHA clamps down: Proposes stronger federal RSI regulations. Infoweek, Nov. 21, 20.

Ubols, Jeff. 1992. Epidemic of job-related injuries puts ergonomics on managers' agendas. Macweek, Sept. 14, 22.

U.S. Department of Labor, Occupational Safety and Health Administration. 1991. Working safely with video display terminals. OSHA: 3092 (revised).

\section{Statement of Ownership, Management, and Circulation}

Library Resources \& Technical Services, Publication No. 311-960 is published quarterly by the Association for Library Collections \& Technical Services, American Library Association, 50 E. Huron St., Chicago (Cook), Illinois 60611-2795. The editor is Richard P. Smiraglia, Palmer School of Library and Information Science, Long Island University, Brookville, NY 11548. Annual subscription price, $\$ 27.50$. Printed in U.S.A. with second-class postage paid at Chicago, Illinois. As a nonprofit organization authorized to mail at special rates (DMM Section 424.12 only), the purpose, function, and nonprofit status of this organization and the exempt status for federal income tax purposes have not changed during the preceding twelve months.

\section{Extent and Nature of Circulation}

(Average figures denote the average number of copies printed each issue during the preceding twelve months; actual figures denote actual number of copies of single issue published nearest to filing date: July 1995 issue.) Total number of copies printed: average 7,450; actual 7,400. Sales through dealers, carriers, street vendors, and counter sales: none. Mail subscription: average 6,843; actual 6,873. Free distribution: average 75; actual 61. Total distribution: average 6,918; actual 6,934. Office use, leftover, unaccounted, spoiled after printing: average 532; actual 466 . Total: average 7,450; actual 7,400. Percentage paid: average 98.92; actual 99.12.

Statement of Ownership, Management, and Circulation (PS Form 3526, Oct. 1995) for 1995/96 filed with the United States Post Office Postmaster in Chicago, October 2, 1995. 